\title{
Analisa Hubungan Antara Disiplin Kerja, Budaya Organisasi Dengan Kinerja Karyawan Dalam Perusahaan
}

\author{
Dedy Syahyuni \\ Universitas Bina Sarana Informatika, dedy.ddn@bsi,ac,id
}

\begin{abstract}
ABSTRAK
Dalam era yang serba cepat seperti sekarang ini, sebuah organisasi dalam hal ini perusahaan juga dituntut untuk dapat bekerja dengan cepat selain harus efektif juga efisien. Oleh karena itu, tidak dapat dipungkiri lagi, terbangun sebuah ekspektasi yang tinggi terhadap performa dari para karyawan dalam setiap perusahaan. Karyawan diminta untuk dapat memberikan pencapaian ekspektasi tersebut. Baik ekspektasi sebagai individu maupun sebagai bagian dari sebuah tim kerja. Oleh karna begitu banyak hal yang perlu diperhatikan dalam peningkatan kinerja maka perusahaan harus memperhatikan beberapa hal teresebut. Dua diantaranya adalah disiplin kerja yang baik dan budaya kerja yang ideal. Kedua hal ini bukan penentu dari kinerja akan tetapi dua hal ini merupakan penyumbang dari terjadinya kinerja karyawan. Tujuan dari tulisan ini adalah untuk memberikan gambaran bahwa variabel disiplin kerja dan budaya organisasi memberikan pengaruh terhadap terciptanya kinerja karyawan. Dalam tulisan ini didapatkan hasil bahwa variebl disiplin kerja dan budaya organisasi berhubungan sebesar 0,636 yang artinya ada hubungan yang kuat dan memberikan pengaruh sebesar 40 persen terhadap terbentuknya kinerja karyawan.
\end{abstract}

Kata Kunci : Disiplin kerja, Budaya Organisasi, Kinerja

\begin{abstract}
In this fast-paced era like today, an organization in this case the company is also required to be able to work quickly in addition to being effective and efficient. Therefore, it cannot be denied, there is a high expectation of the performance of the employees in each company. Employees are asked to be able to provide the achievement of these expectations. Both expectations as individuals and as part of a work team. Because so many things that need to be considered in improving performance, the company must pay attention to some of these things. Two of them are good work discipline and ideal work culture. Both of these are not determinants of performance but these two things are a development of employee performance. The purpose of this paper is to provide an overview of work discipline and organizational culture and their contrubution on the creation of employee performance. In this paper, the results show that work discipline variables and organizational culture are related to 0.636, which means there is a strong relationship and gives an effect of 40 percent on the formation of employee performance.
\end{abstract}

Keywords: Dicipline, organizational culture, work Performance

Naskah diterima: 26-08-2020, direvisi: 23-06-2020, diterbitkan: 01-09-2020

PENDAHULUAN

Dalam meningkatkan kinerja dari para karyawan ada banyak yang harus diperhatikan oleh perusahaan karena karyawan bukanlah sebuah mesin yang tidak bernyawa dan berkehendak. Selayaknya sebagai manusia 
dewasa yang normal, ada banyak hal yeng mempengaruhi para karyawan dalam bekerja. Jadi bukan hanya peningkatan keterampilan saja yang membuat karyawan memiki kinerja yang tinggi atau bukan hanya perhatian pimpinan saja yang membuat karyawan memberikan kinerja yang baik tetapi lebih dari itu.

Dalam ilmu menejemen sumber daya manusia, kinerja juga merupakan hal yang sering dikaji bukan hanya karena bahasannya yang menarik akan tetapi ada banyak sudut pandang dalam melihat bagaimana dan apa saja yang dapat dipakai oleh perusahaan dalam meningkatkan kinerja dari karyawannya. Mulai dari upaya peningkatan dari segi intern bahkan dari ekstern diri dari para karyawan. Dalam praktenya ada kesenjangan diantara pencapaian kinerja karyawan dan upaya peningkatan disiplin kerja dan pelaksanaan budaya organisasi. Banyak perusahaan mencoba meningkatkan kinerja hanya pada bagaimana peningkatan keterampilan dan kompensasi saja. Dalam beberapa penelitan dapat terlihat bahwa ada beberapa hal lain yang membuat kinerja karyawan dapat meningkat bahkan turun bukan hanya dari keterampilan atau mompensasi. Oleh karena itu dalam tulisan ini penulis mencoba mambahas sejauh mana variabel disiplin kerja dan budaya organisasi memberikan dampak terhadap terjadinya kinerja karyawan.

\section{KAJIAN LITERATUR \\ Disiplin Kerja}

Menurut (Hasibuan, 2016) dalam bukunya, beliau menyebutkan bahwa disipin kerja merupakan fungsi operatif keenam dari pembahasan manajemen sumber daya manusia. Lebih 1 disebutkan bahwa bukan hanya sebagai fungsi operatif saja akan tetapi disiplin kerja adalah salah satu faktor terpenting dari manajemen sumber daya manusia.

Hal ini karena semakin baik atau tinggi disipin kerja para karyawan maka semakin tinggi pula tingkat prestasi kerja dari para karyawannya. Dilain pihak bila disiplin kerja dari para karyawan di perusahaan itu buruk atau rendah maka akan berdampak pada sulitnya pencapaian hasil yang optimal.
Siagian mengutarakan pendapat seperti yang dikutip oleh (Sutrisno, 2016) Terdapat bentuk disiplin kerja yang ideal akan dapat terlihat dari suasana, seperti :

Terdapat rasa keperdulian dari para karyawan terhadap cara pencapaian tujuan dari perusahaan yang cukup tinggi.

Terdapat motivasi dan gairah kerja dan juga insiatif yang cukup tinggi dari para karyawan di perusahaan dalam melakukan pekerjaan yang dibebankan kepada mereka.

Tingginya perasaan tanggung jawab dari para karyawan di dalam organisasi untuk melaksanakan tugas yang dibebankan kedapa meraka dengan sebaik-baiknya.

Adanya peningatan yang terus menerus atas rasa memiliki dan kebersamaan dikalangan karyawan.Berkembangnya tingkat efisiensi dan produktivitas kerja dari para karyawan dalam perusahaan.

\section{Budaya Organisasi}

Menurut (Robbins, Stephen P \& Judge, 2017) dalam bukunya, pengertian dari Budaya Organisasi adalah sebuah sistem atau tata aturan yang di jalankan oleh para anggota dari suatu organisasi yang dapat menjadi pembeda antara diri mereka dengan anggota dari organisasi lainnya.

Robert Kreitner dan Angelo Kinicki berpendapat dalam buku dari (Wibowo, 2016) adalah, terdapat beberapa fungsi budaya organisasi. Hal ini menunjukkan bagaimana peranan serta kegunaan budaya organisasi :

Menyematkan simbol dan identitas dari setiap anggota, menjadikan jatidiri dari perusahaan diakui sebagai organiasi modern dengan menciptakan produk yang inovatif. jatidiri organisasi mencerminkan simbol dan ciri unik yang dapat memberikan pembedakan dengan organisasi sejenis yang juga mempunyai sifat yang juga berbeda.

Memfasilitasi terbentuknya sebuah komitmen bersama, perusahaan mampu membangun perasaan dari para pekerjanya untuk bangga dapat menjadi bagian dari perusahaan. Anggota organisasi memiliki komitmen kolektif atas tataaturan yang berlaku didalam organisasi yang harus mereka ikuti dan pencapaian tujuan perusahaan.

Berkembangnya stabilitasasi sistem sosial dalam perusahaan sehinga dapat mengambarkan suatu lingkungan kerja yang positif dan diperkuat, adanya konflik yang 
terjadi dan perubahan dapat dikelola secara secara tepat. Dengan adanya sebuah kesepakatan kolektif tentang budaya organisasi yang harus laksanakan mampu membuat situasi lingkungan dan interaksi sosial dapat berjalan dengan stabil dan tanpa adanya rintangan.

Membentuk Sikap dan pemikiran dengan membantu para karyawan memahami atas lingkungan kerja mereka. Budaya Organsasi dapat berfungsi sebagai alat untuk menjadikan karyawan berfikir positif dan logis.

\section{Kinerja}

Menurut pendapat dari (Suwatno, 2016), kinerja yang dalam bahasa Inggris disebut sebagai performance atau dalam bahsa Indonesia juga disebut dengan unjuk kerja. Lebih lanjut disebutakan bahwa kinerja dapat pula diartikan sebagai prestasi kerja atau juga disebut sebagai pelaksanaan kerja atau hasil dari unjuk kerja.

Menurut buku dari (Siagian, 2015), Pentingnya dari penilaian kinerja dari para karyawan yang didasari atas rasonalitas dan penerapannya yang objektif dalam atri tidak ada subjetifitas atau kecenderungan pribadi penilain dalam terlihat dari dua macam kepentingan yang mewakilinya, dua kepentingan tersebut adalah kepentingan para pegawai yang dinilai dan juga kepentingan dari organisasi dari tempat karyawan tersebut dinilai.

Menurut pendapat dari Harmani Pasolong dalam buku karangan (Fahmi, 2016) Kinerja memiliki beberapa bagian, seperti berikut :

Hasil kerja merupakan hasil akhir secara perseorangan atau secara institusi, yang artinya kinerja tersebut adalah suatu hasil akhir yang didapatkan secara personal atau grup.

Dalam menjalankan kewajiban, perseorangan atau organisasi diberi kewewenangan dan juga tanggung jawab, yang artinya orang atau organisasi diberikan kewenangan dan kekuasaan untuk dipakai, sehingga para pekerjaan bisa bekerja dengan baik

Pekerjaan yang dijalankan wajib berdasarkan aturan resmi dan sesuai ketentuan, artinya dalam menjalankan kewajiban para karyawan atau organisasi tentu wajib mengikuti peraturan yang ditetapkan oleh perusahaan.
Tugas atau pekerjaan yang dijalankan tidak boleh bertentangan dengan aturan dari moral serta etika, yang artinya selain mematuhi peraturan yang berlaku, sudah pasti pekerjaaan tersebut haruslah dimulai oleh adanya kesesuaian dengan moral serta etika yang berlaku.

\section{METODE PENELITIAN}

Dalam memaparkan tulisan ini penulis menggunakan metode penelitian deskriptif kuantitatif, dimana penulis mencoba menghubungkan beberapa variabel penelitian yang dipilih yaitu disiplin kerja, Budaya oragnisasi dan kinerja karyawan.

Adapun dugaan awal dalam tulisan in adalah adanya hubungan antara disipin kerja, budaya organisasi dan kinerja karyawan. Dalam perhitungan, penulis menetapkan tingkat signifikansi $5 \%$ dan sample yang dipakai adalah sample jenuh dimana sebanyak 35 orang dari karyawan dari bagian Sumber daya manusia pada PT Kereta Api (cikini) Jakarta dijadikan sebagai sample.

Dalam proses perhitungan statistik penulis menggunakan bantuan dari Microsoft Excel dan aplikasi SPSS Versi 21 dan yang dihitung adalah validitas, reabilitas, uji normalitas, multikolinieritas, heterokedaksitas, Korelasi, determinasi dan regresi.

Sedangkan hipotesa dari tulisan ini adalah adanya hubungan antara ketiga jariabel yang dipakai, yaitu disiplin kerja dan budaya organisasi berhubungan dengan kinerja karyawan.

\section{PEMBAHASAN}

Berdasarkan hasil perhitungan data awal yakni dalam perhitungan validitas dengan menggunakan bantuan aplikasi SPPP versi 21 maka didapatkan hasil sebagai berikut.

Tabel 1 Validitas disiplin kerja

\begin{tabular}{|c|c|c|c|}
\hline No & Tabel R & Nilai Hitung & Keterangan \\
\hline 1 & 0,344 & 0,685 & valid \\
\hline 2 & 0,344 & 0,738 & valid \\
\hline 3 & 0,344 & 0,662 & valid \\
\hline 4 & 0,344 & 0,684 & valid \\
\hline 5 & 0,344 & 0,761 & valid \\
\hline 6 & 0,344 & 0,463 & valid \\
\hline
\end{tabular}




\begin{tabular}{|c|c|c|c|}
7 & 0,344 & 0,703 & valid \\
\hline 8 & 0,344 & 0,716 & valid \\
\hline 9 & 0,344 & 0,514 & valid \\
\hline 10 & 0,344 & 0,615 & valid \\
\hline 11 & 0,344 & 0,549 & valid \\
\hline 12 & 0,344 & 0,674 & valid \\
\hline
\end{tabular}

Sumber SPSS Versi 21

Dapat dilihat dari hasil perhitungan yang ada dalam tabel maka dikatakan bahwa semua pertanyaan (item) dinyakatan valid

Dengan menggunakan aplikasi yang sama maka dilanjutkan dengan perhitungan validtas dari variabel budaya organisasi maka didapatkan hasil sebagai berikut

Tabel 2 Validitas Budaya Organisasi

\begin{tabular}{|c|c|c|c|}
\hline No & Tabel R & Nilai Hitung & Keterangan \\
\hline 1 & 0,344 & 0,205 & tidak valid \\
\hline 2 & 0,344 & 0,458 & valid \\
\hline 3 & 0,344 & 0,477 & valid \\
\hline 4 & 0,344 & 0,751 & valid \\
\hline 5 & 0,344 & 0,678 & valid \\
\hline 6 & 0,344 & 0,698 & valid \\
\hline 7 & 0,344 & 0,689 & valid \\
\hline 8 & 0,344 & 0,719 & valid \\
\hline 9 & 0,344 & 0,522 & valid \\
\hline 10 & 0,344 & 0,772 & valid \\
\hline 11 & 0,344 & 0,452 & valid \\
\hline 12 & 0,344 & 0,743 & valid \\
\hline
\end{tabular}

Sumber: SPSS Versi 21

Berdasrkan hasil perhitungan validitas atas variabel penelitian budaya organisasi bahwa terdapat satu item tidak valid dan sebelihnya dinyatakan valid.

Selanjutnya dilakukan perhitungan dari variabel kinerja dan hasil dari uji validitas dengan dengan bantuan SPSS versi 21 didapatkan hasil sebagai berikut:

Tabel 3 Validitas Kinerja

\begin{tabular}{|r|l|l|c|}
\hline No & Tabel R & Nilai Hitung & Keterangan \\
\hline 1 & 0,344 & 0,732 & valid \\
\hline 2 & 0,344 & 0,667 & valid \\
\hline 3 & 0,344 & 0,655 & valid \\
\hline
\end{tabular}

\begin{tabular}{|r|l|l|l|}
4 & 0,344 & 0,656 & valid \\
\hline 5 & 0,344 & 0,480 & valid \\
\hline 6 & 0,344 & 0,757 & valid \\
\hline 7 & 0,344 & 0,503 & valid \\
\hline 8 & 0,344 & 0,576 & valid \\
\hline 9 & 0,344 & 0,579 & valid \\
\hline 10 & 0,344 & 0,207 & tidak valid \\
\hline 11 & 0,344 & 0,525 & valid \\
\hline 12 & 0,344 & 0,811 & valid \\
\hline
\end{tabular}

Sumber : SPSS versi 21

Dari hasil perhitungan variabel kinerja didapatkan hasil bahwa terdapat 1 item dinyatakan tidak valid yaitu item nomor 10 .

Selanjutnya dalam pengujian perhitungan rebailitas dari ketiga variabel dalam penelitian ini didapatkan hasil sebagai berikut :

Tabel 4 Reabilitas

\begin{tabular}{|l|c|c|}
\hline Variabel & Reabilitas & Keterangan \\
\hline Disiplin Kerja & 0,865 & Tinggi \\
\hline Budaya Organisasi & 0,837 & Tinggi \\
\hline Kinerja & 0,828 & Tinggi \\
\hline
\end{tabular}

Sumber SPSS versi 21

Dari hasil perhitungan reabilitas dari ketiga variabel maka didapatkan hasil bahwa semua variabel memiliki tingkat reabilitas yang tinggi.

Langkah selanjutnya adalah melakukan uji klasik. Uji klasik yang dilakukan pertama kali adalah uji Normalitas. Dlam uji normalitas, seperti halnya dalam uji validitas dan uji reabilitas maka perhitungan dilakukan dengan bantuan SPSS dan hasilnya adalah :

Tabel 5 Uji Normalitas

One-Sample Kolmogorov-Smirnov Test

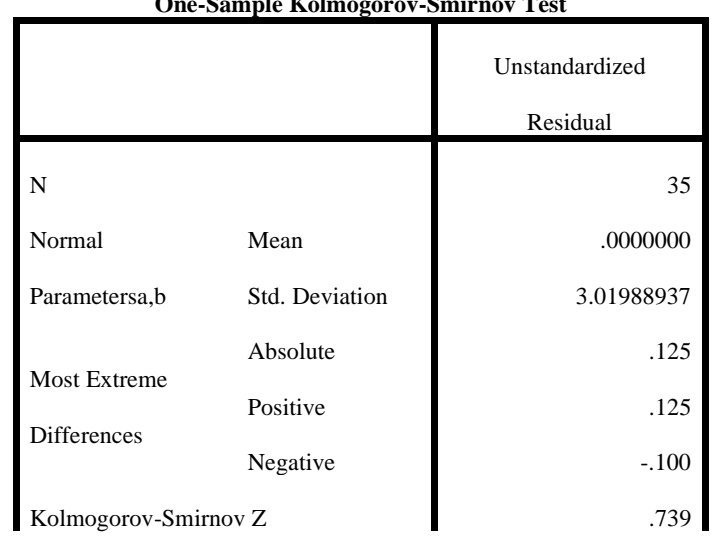


Asymp. Sig. (2-tailed)

a. Test distribution is Normal

b. Calculated from data.

Sumber : SPSS versi 21

Sebaran data dalam peneltian ini memperlihatkan adanya sebaran data yang normal karena dapat terlihat sahil yang nyatakan angka 0,645 atau lebih dari 0,05 pada Symp Sig. dalam hal ini dapat dikatakan bahwap perhitungan dapat dilanjutkan dengan menghitung multikoliniear.

Dalam uji multikolinear dengan bantuan SPSS versi 21 didapatkan hasil sebagai berikut.

Tabel 6 Uji Multikolinieritas

\section{Coefficients $^{\mathrm{a}}$}

\begin{tabular}{|c|c|c|c|c|c|c|c|}
\hline \multirow[t]{2}{*}{ Model } & \multicolumn{2}{|c|}{$\begin{array}{l}\text { Unstanda } \\
\text { rdized } \\
\text { Coefficie } \\
\text { nts }\end{array}$} & \multirow{2}{*}{\begin{tabular}{|l} 
Stan \\
dard \\
ized \\
Coe \\
ffici \\
ents \\
Beta
\end{tabular}} & \multirow[t]{2}{*}{$\mathrm{t}$} & \multirow[t]{2}{*}{$\begin{array}{l}\mathrm{Si} \\
\mathrm{g} .\end{array}$} & \multicolumn{2}{|c|}{$\begin{array}{c}\text { Colline } \\
\text { arity } \\
\text { Statistic } \\
\text { s }\end{array}$} \\
\hline & B & $\begin{array}{c}\text { Std. } \\
\text { Erro } \\
\text { r }\end{array}$ & & & & $\begin{array}{l}\text { To } \\
\text { ler } \\
\text { an } \\
\text { ce }\end{array}$ & $\begin{array}{c}\text { VI } \\
\text { F }\end{array}$ \\
\hline $\begin{array}{l}\text { (Co } \\
\text { nsta } \\
\text { nt) }\end{array}$ & $\begin{array}{r}21 . \\
36 \\
9\end{array}$ & $\begin{array}{r}6.42 \\
7\end{array}$ & & $\begin{array}{r}3.3 \\
25\end{array}$ & $\begin{array}{r}.00 \\
2\end{array}$ & & \\
\hline $\begin{array}{ll} & \text { DIS } \\
1 & \text { IPLI } \\
& \mathrm{N}\end{array}$ & $\begin{array}{r}.09 \\
1\end{array}$ & .194 & .105 & $\begin{array}{r}.47 \\
1\end{array}$ & $\begin{array}{r}64 \\
1\end{array}$ & $\begin{array}{r}.37 \\
7\end{array}$ & $\begin{array}{r}2.6 \\
55\end{array}$ \\
\hline $\begin{array}{l}\text { BU } \\
\text { DA } \\
\text { YA }\end{array}$ & $\begin{array}{r}.49 \\
4\end{array}$ & .200 & .550 & $\begin{array}{r}2.4 \\
72\end{array}$ & $\begin{array}{r}.01 \\
9\end{array}$ & $\begin{array}{r}.37 \\
7\end{array}$ & $\begin{array}{r}2.6 \\
55\end{array}$ \\
\hline
\end{tabular}

a. Dependent Variable: KINERJA

\section{Sumber SPSS Versi 21}

Dari tabel multikolinier diatas dapat dilahat bahwa hasil dari tolerance adalah 0,337 dan VIF adalah 2,655 yang artinya hubungan antara variabel dalam hal ini disiplin kerja, budaya organisasi dan kinerja karyawan tidak ada mutikolinier dan artinya perhitngan dapat dilanjutkan ke perhitungan heterokedaksitas.
Berikutnya dalam perhitungan atau uji heterodekasitas dari ketiga variabel dalam tulisan ini didaptakan hasil sebagai berikut.

Tabel 7 Uji Heterokedaksitas

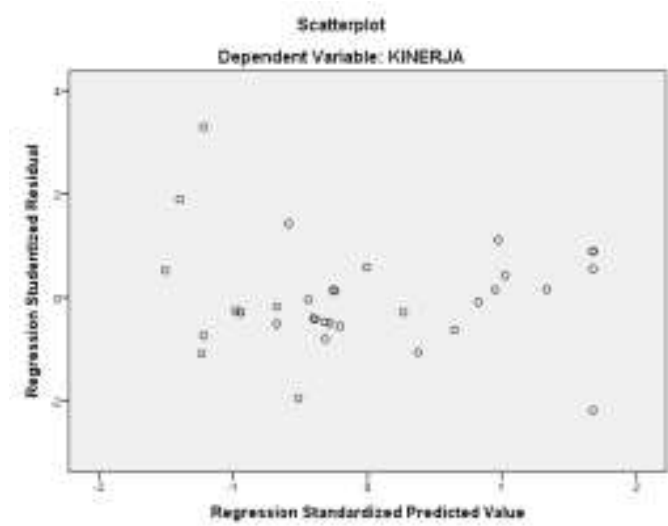

\section{Sumber SPSS Versi 21}

Dari hasil perhitungan diatas dapat disimpulkan bahwa tidak terjdi keraguan atau ketidak akuratan data. Hal ini terlihat dari tidak adanya pola atau pola tidak berbentuk seperti gelombang. Gambar juga tidak berkumpul dan berada diantara titik nol.

Karena dari ektiga uji ditas dinyatakan baik atau tidak ditemukan masalah maka perhitungan beriktunya adalah uji determinasi.

Dari hasl uji determinasi maka didapatkan hasil sebagai berikut :

Tabel 8 Uji Korelasi dan Deterimasi

\begin{tabular}{|c|c|c|c|c|}
\hline \multicolumn{5}{|c|}{ Model Summary ${ }^{\mathbf{b}}$} \\
\hline Model & $\mathrm{R}$ & $\begin{array}{c}\mathrm{R} \\
\text { Square }\end{array}$ & $\begin{array}{c}\text { Adjusted R } \\
\text { Square }\end{array}$ & $\begin{array}{l}\text { Std. Error of } \\
\text { the Estimate }\end{array}$ \\
\hline & $.636^{\mathrm{a}}$ & .404 & .367 & 3.113 \\
\hline
\end{tabular}

a. Predictors: (Constant), BUDAYA, DISIPLIN

b. Dependent Variable: KINERJA

Sumber SPSS Versi 21

Dalam uji korelasi dan deterimasi atas ketiga variabel yaitu disiplin kerja, budaya oragnisasi dan kinerja maka didapatkan hasil bahwa terdapat angka 0,636 yang artinya ada 
hubungan yang kuat karena ada dalam kisaran 0,60 sampai 0,799 .

Hal yang hampir sama dari hasil penetian yang dilakukan oleh (Harjanti, 2019) dimana terdapat hubungan yang juga baik yaitu sebesar 0,837. Jadi kedua penelitan ini memiliki hasil yang keduanya dikategorikan baik.

Dalam penelitian dengan variabel tiga yang sama dalam penelitian yang dilakukan oleh (Ibrahim, 2020) yang menyatakan bahwa terdapat korelasi yang cukup signifikan diantara ketiga variabel. Didapatkan hasil dengan tingkat 0,808 jadi ketiga penelitina ini memiliki kesamaan yang cukup baik.

Sedangkan dalam uji determinsai didapatkan angka sebesar 0.404 yang artinya kedua variabel independent dalam hal ini variable disiplin dan budaya organisasi kontribusi sebesar 40 persen terhadap terbentuknya kinerja karyawan dan selebihnya, sekitar 60 persen dipengaruhi oleh variabel lain yang dalam hal ini tidak dihitung dalam penelitian.

Dalam kesempatan yang berbeda, dengan ketiga variabel yang sama diungkapkan dari hasil penelitian oleh (Putri, Dewi Yolanda \& Novi, 2020) didapatkan hasil determinasi sebesar 21,8 persen dan sisanya sebesar 72,8 dipengaruhi oleh variabel yang lain.

Selanjutnya dalam penelitian yang dilakukan oleh (Sularmi, 2019) didapatkan hasil dimana ketiga variabel yang sama memiliki kesamaan yaitu disiplin dan budaya menjadi variabel yang mempengaruhi dan kinerja adalah variabal yang dipengaruhi dan terdapat 52,7 persen kontribisi dari variabel budaya dan disiplin terhadap terjadinya kinerja karyawan.

Tabel 9 Anova

ANOVA ${ }^{a}$

\begin{tabular}{|r|r|r|r|r|r|}
\hline Model & $\begin{array}{l}\text { Sum of } \\
\text { Squares }\end{array}$ & df & $\begin{array}{c}\text { Mean } \\
\text { Square }\end{array}$ & F & Sig. \\
\hline $\begin{array}{r}\text { Regre } \\
\text { ssion }\end{array}$ & 210.101 & 2 & 105.050 & 10.841 & $.000^{\mathrm{b}}$ \\
1 Resid & 310.071 & 32 & 9.690 & & \\
ual & & & & & \\
Total & 520.171 & 34 & & & \\
\hline
\end{tabular}

a. Dependent Variable: KINERJA

b. Predictors: (Constant), BUDAYA, DISIPLIN

\section{Sumber SPSS Versi 21}

Dari hasil perhitungan dengan bantuan SPSS Versi 21 maka diapatkan dalam uji anova angka sebesar 0,000 dalam Sig yang artinya kedua variabel dalam hal ini budaya organisasi dan disiplin kerja secara nyata memang mempengaruhi variabel kinerja

Tabel 10 Uji Regresi

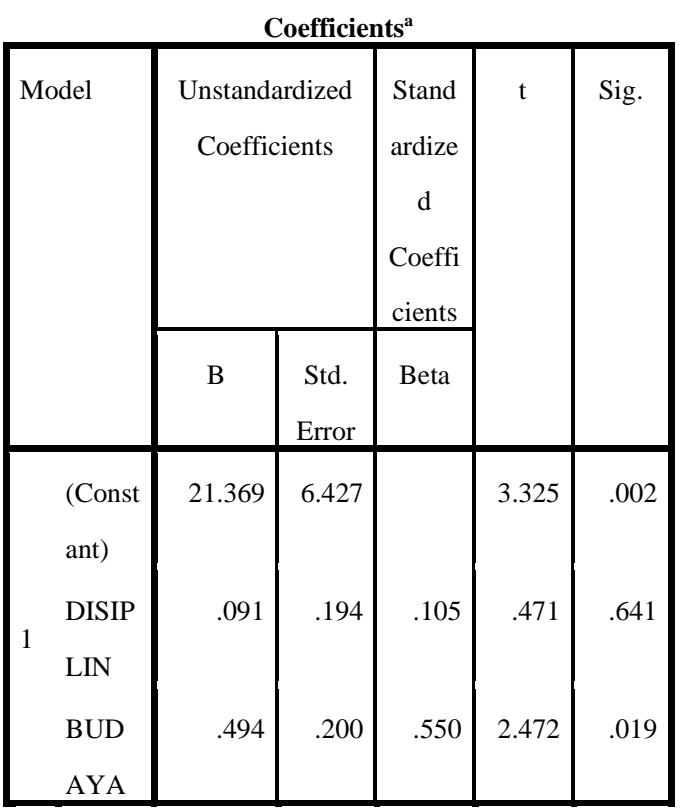

a. Dependent Variable: KINERJA

\section{Sumber : SPSS Versi 21}

Dari hasil uji Regresi ditas maka ditemukan persamaan baru dalam kasus penulisan ini sebagai berikut :

$Y=21.369+0,091+0,494$

Dimana bila ada pertambahan sebesar 1 satuan pada variabel disiplin akan merubah hasil persamaan menjadi 0,091 dan begitu pula sebaliknya dan pada varaiebl budaya didapatkan apabila adanya perusabahan penambahan sebesar 1 satuan maka akan menambah jumlah persamaan menjadi 0,494.

\section{PENUTUP}

Dari hasil perhitungan data kuisioner yang disebarkan penulis kedalam perusahaan dalam hal ini divisi Sumber Daya Manusia pada PT Kereta Api Daerah Operasi 1, maka didapatkan hasil bahwa terdapat hubungan 
yang kuat diantara ketiga variabel yang dipakai dalam penelitian yaitu disipin kerja, budaya organisasi dan kinerja karyawan. Hal in terlihat dari angka yang ditampilkan sebesar 0,636.

Lalu dalam perhitungan atau uji determinasi yang dilakukan dengan bantuan dari aplikasi SPSS Versi 21 diapatkan bahwa ada kontribusi dari kedua variabel (budaya organisasi dan disiplin kerja) terhadap terjadinya kinerja karyawan dan didapatkan angka sebenar 40 persen. Selebihnya sebenear 60 persen dipengaruhi oleh variabel lain,

Karena masih besarnya variabel lain yang mempengaruhi kinerja karyawan maka akan lebih baik dilakukan penelitian lanjutan untuk mengetaui variabel apakah itu dan berapa besaranya sehingga perusahaan dapat mempertahankan bahkan meningkatkan angka kinerja karyawan.

\section{REFERENSI}

Fahmi, I. (2016). Perilaku Organisasi. Bandung: Alfabeta.

Harjanti, M. \& W. F. (2019). Pengaruh Budaya Organisasi , Disiplin Kerja Dan Komunikasi Terhadap Kinerja Pegawai Negeri Sipil ( Pns ) Pada Balai Besar Wilayah Sungai ( Bbws ) Pemali Juana Semarang Mudji Harjanti * \& Wachid Fuady R ** STIE Dharmaputra Semarang Latar Belakang Masalah S. Ekonomi Manajemen Akutansi, 48(26), 33-42. https://ejurnal.stiedharmaputrasmg.ac.id/index.php/JEMA/article/view/ 372

Hasibuan, M. (2016). Manajemen Sumber Daya Manusia. Jakarta: Bumi Aksara.

Ibrahim, M. \& E. (2020). Pengaruh Budaya
Organisasi Dan Disiplin Kerja Terha Dap Kinerja Pegawai Di Kantor Desa Timoreng Panua Kecamatan Pan Ca Rijang Kabupaten Sidenreng Rappang. Praja, $8(1)$ https://jurnal.umsrappang.ac.id/praja/arti cle/view/202.

Putri, Dewi Yolanda \& Novi, S. (2020). Pengaruh Disiplin Kerja Dan Budaya Organisasi Terhadap Kinerja Pada Karyawan PT Aurora World Cianjur. Manners, 2(2).

Robbins, Stephen P \& Judge, T. A. (2017). Perilaku Organisasi (16th ed.). jakarta: Salemba Empat.

Siagian, S. P. (2015). Manajemen Sumber Daya Manusia. Jakarta: Bumi AKsara.

Sularmi, L. \& nur H. (2019). Pengaruh Budaya Organisasi Dan Disiplin Terhadap Kinerja Karyawan Pada PT. Mega Perintis Tbk. Jurnal Ilmiah Sumber Daya Manusia, 3(1), 125-139, http://openjournal.unpam.ac.id/index.ph p/JJSDM/article/view/3373

Sutrisno, E. (2016). Manajemen Sumber Daya Manusia (8th ed.). Jakarta: Kencana.

Suwatno. (2016). Manajemen Sumber Daya Manusia. Bandung: Alfabeta.

Wibowo. (2016). Budaya Organisasi (2nd ed.). Jakarta: Rajagrafindo.

\section{BIODATA PENULIS}

Dedy Syahyuni SIP SE MM (Jakarta,1973) Lulus dari SMAN 8 Jakarta tahun 1992 lalu menyelesaikan jenjang Strata 1 jurusan Adminitrasi Negara dari Faktutas Ilmu Sosial dan Ilmu Politik (Universitas Nasional Jakarta), Strata 1 Jurusan Manajemen dari Fakultas Ekonomi (Universitas Satyagama Jakarta), Janjang Strata 2 Magister Manajemen (Universitas Krisnadwipayana Jakarta). Mulai mengajar di Universitas Bina Sarana Informatika dari tahun 2000 sampai sekarang 